\title{
Virulence Gene Profiles of Multidrug-Resistant Pseudomonas aeruginosa Isolated From Iranian Hospital Infections
}

\author{
Nastaran Fazeli ${ }^{1}$; Hassan Momtaz ${ }^{1, *}$ \\ ${ }^{1}$ Department of Microbiology, Shahrekord Branch, Islamic Azad University, Shahrekord, IR Iran \\ ${ }^{*}$ Corresponding Author: Hassan Momtaz, Department of Microbiology, Shahrekord Branch, Islamic Azad University, Shahrekord, IR Iran. Tel: +98-9133812574, E-mail: hamomtaz@ \\ yahoo.com
}

Received: October 28, 2013; Revised: December 25, 2013; Accepted: January 18, 2014

\begin{abstract}
Background: The most common hospital-acquired pathogen is Pseudomonas aeruginosa. It is a multidrug resistant bacterium causing systemic infections.

Objectives: The present study was carried out in order to investigate the distribution of virulence factors and antibiotic resistance properties of Pseudomonas aeruginosa isolated from various types of hospital infections in Iran.

Patients and Methods: Two-hundred and seventeen human infection specimens were collected from Baqiyatallah and Payambaran hospitals in Tehran, Iran. The clinical samples were cultured immediately and samples positive for P. aeruginosa were analyzed for the presence of antibiotic resistance and bacterial virulence genes using PCR(polymerase chain reaction). Antimicrobial susceptibility testing was performed using disk diffusion methodology with Müeller-Hinton agar.

Results: Fifty-eight out of 127 (45.66\%) male infection specimens and 44 out of 90 (48.88\%) female infection specimens harbored $P$. aeruginosa. Also, $65 \%$ (in male specimens) and 21\% (in female specimens) of respiratory system infections were positive for $P$. aeruginosa, which was a high rate. The genes encoding exoenzyme $S$ (67.64\%) and phospholipases $C(45.09 \%)$ were the most common virulence genes found among the strains. The incidences of various $\beta$-lactams encoding genes, including $b l a_{\mathrm{TEM}}, b l a_{\mathrm{SH}}, b l a_{\mathrm{OXA}}, b l a_{\mathrm{CTX}-\mathrm{M}}, b l a_{\mathrm{DHA}}$, and bla $_{\mathrm{VEB}}$ were $94.11 \%, 16.66 \%, 15.68 \%, 18.62 \%, 21.56 \%$, and $17.64 \%$, respectively. The most commonly detected fluoroquinolones encoding gene was gyrA (15. 68\%). High resistance levels to penicillin (100\%), tetracycline (90.19\%), streptomycin (64.70\%), and erythromycin (43.13\%) were observed too.

Conclusions: Our findings should raise awareness about antibiotic resistance in hospitalized patients in Iran. Clinicians should exercise caution in prescribing antibiotics, especially in cases of human infections.
\end{abstract}

Keywords:Pseudomonas aeruginosa; Virulence Factors; Hospital infections; Iran

\section{Background}

Pseudomonas aeruginosa (P. aeruginosa) is an opportunistic pathogen causing a wide range of human infections. It is a common hospital-acquired pathogen and responsible for urinary tract infections (UTIs), respiratory infections, dermatitis, soft tissue infections, bacteremia, bone and joint infections, gastrointestinal infections, and a variety of systemic infections, particularly in patients with severe burns, bed ulcers, and in patients suffered from cancer or AIDS who are immunosuppressed (1-3). P. aeruginosa has been associated with a high rate of morbidity, and its mortality rate was reported from $18 \%$ to $61 \%$ in hospital-acquired infections $(2,4,5)$.

$P$. aeruginosa virulence factors are related to its adhesions and other secreted toxins. The phenazine operons ( $p h z I$ and $p h z I I$ ) and genes ( $p h z H, p h z M$, and $p h z S$ ) encode precursor proteins involved in the formation of three phenazine compounds passively secreted by $P$. aeruginosa: pyocyanin, 1-hydroxyphenazine, and phenazine1-carboxamide $(6,7)$, which are responsible for increasing intracellular oxidative stress (6). P. aeruginosa also has a large number of other virulence factors such as exotoxin A (exoA), alkaline protease (aprA), exoenzyme $S$, $\mathrm{U}$, and $\mathrm{T}$ (exoS, exoU, exoT), elastase and sialidase, which are exo $A$ gene and virulence factor exoS secretions by a type III section system (8-10). A zinc metalloprotease called lasB has an elastolytic activity on human tissue and especially lung tissue (11). The gene called nan1 encodes sialidase, which is responsible for adherence to the cells (11). The phospholipids contained in pulmonary surfactants may be hydrolysed by two phospholipases $C$ encoded by $p l c H$ and plcN. An extracellular neuraminidase is thought to play an important role in implantation of the bacterium (11).

Despite using potent antibiotics, invasive $P$. aeruginosa infection is associated with high mortality (12). In the past decade, acquired multidrug resistance, because of selective antibiotic pressure, has emerged in several countries; and in some cases, infections caused by multidrug resistant $P$. aeruginosa have been untreatable (13). A previous study addressed that the Iranian isolates of 
P. aeruginosa were resistant to trimethoprim (100\%), amoxicillin (100\%), ampicillin (100\%), tetracycline (100\%), ticarcillin (100\%), carbenicillin (90\%), ceftazidime (80\%), clavulanic acid (69.2\%), imipenem (60\%), cefepime (52\%), gentamicin (50\%), and ciprofloxacin (40\%) (14). Similar incidence of antibiotic resistance among $P$. aeruginosa strains in other countries has been reported previously $(12,15-17)$. This high antibiotic resistance of $P$. aeruginosa was against commonly used antibiotics and especially $\beta$-lactams, including broad-spectrum cephalosporins, quinolones, chloramphenicol, and tetracyclines, mainly encoded by several antibiotic resistance genes, including bla $a_{\mathrm{TEM}}$, bla $_{\mathrm{SHV}}$, bla ${ }_{\mathrm{OXA}}, b l a_{\mathrm{CTX}-\mathrm{M}}$, bla $a_{\mathrm{DHA}}$ and $b l a_{\mathrm{VEB}}(18)$.

\section{Objectives}

There was no comprehensive investigation about the molecular characterization and antimicrobial resistance properties of $P$. aeruginosa isolated from human clinical samples in Iran. Therefore, the present study was carried out in order to investigate the distribution of virulence and antibiotic resistance genes as well as the pattern of antibiotic resistance of $P$. aeruginosa isolated from Iranian hospitalized patients who suffered from UTIs, respiratory infections, burn infections, bed ulcers, and wound infections.

\section{Patients and Methods}

\subsection{Samples and Identification of Pseudomonas aeruginosa}

A total of 217 human clinical samples, including wound infections $(n=62)$, respiratory infections $(n=23)$, urinary tract infections $(n=41)$, bed ulcer $(n=39)$, and burn ( $n$ $=52$ ) were collected from hospitalized male and females who were referred to Baqiyatallah and Payambaran hospitals, Tehran, Iran. All samples were transmitted to Microbiology and Infectious Diseases Research Center of the Islamic Azad University of Shahrekord in a cooler with ice-packs. Samples were placed on the selective medium of Pseudomonas Cetrimide Agar (PCA) (LABOBASI, Mendrisio, Switzerland) using a spreading technique. Plates were incubated for 18-24 hours and observed for suspected colonies of $P$. aeruginosa, which was identified by colony pigmentation, grape-like odor, motility and biochemical tests, including carbohydrate fermentation $(-)$, citrate assimilation $(+)$, lysine decarboxylase $(-)$, indole $(-)$, oxidase $(+)$, beta-hemolysis on blood-agar $(+)$, and DNase (-). Inocula from pure colonies on PCA were cultured on nutrient agar slants and kept at $4^{\circ} \mathrm{C}$.

\subsection{Antibiotic Susceptibility Test}

$P$. aeruginosa isolates were incubated initially on the nutrient agar media (at $4^{\circ} \mathrm{C}$ ) and their positive colonies were transferred to the Müeller-Hinton agar (HiMedia Laboratories, Mumbai, India). Antimicrobial susceptibil- ity was performed on Mueller-Hinton agar by the standard disk diffusion method recommended by Clinical and Laboratory Standards Institute (19). This was done by dipping a sterile swab (stick into an overnight nutrient broth) and carefully swabbing the entire surface of Müeller-Hinton agar plates. The antibiotics used against the test bacteria were as follows: tetracycline (30 $\mu \mathrm{g} / \mathrm{disk})$; streptomycin (10 $\mu \mathrm{g} /$ disk); chloramphenicol (30 $\mu \mathrm{g} / \mathrm{disk})$; sulfamethoxazole $(25 \mu \mathrm{g} /$ disk); gentamicin $(10 \mu \mathrm{g} /$ disk); enrofloxacin $(5 \mu \mathrm{g} /$ disk); cephalothin $(30 \mu \mathrm{g} /$ disk); ciprofloxacin $(5 \mu \mathrm{g} /$ disk); trimethoprim $(5 \mu \mathrm{g} /$ disk); nitrofurantoin $(300 \mu \mathrm{g} /$ disk); ampicillin (10 u/disk); penicillin (10 u/ disk), and erythromycin (15 $\mu \mathrm{g} /$ disk). Then, the antibiotic multidisk (Padtan Teb, Iran) was placed on the surface of the inoculated plates and gently pressed. The plates were incubated at $37^{\circ} \mathrm{C}$ for $18-24 \mathrm{~h}$. The diameter of inhibition zone was measured in millimeters and isolates were scored as sensitive or resistant by comparing with values recommended on standard charts (19). P. aeruginosa ATCC 10145 was used as the quality control organism in antimicrobial susceptibility determination.

\subsection{DNA Extraction and PCR Confirmation}

Chromosomal DNA was extracted from each P. aeruginosa isolate by DNA extraction kit (DNPTM, CinnaGen, Iran) according to manufacturer's instruction. The bacteria were confirmed using the PCR method for nan 1 gene of the P. aeruginosa (20). PCR was carried out with $2 \mu \mathrm{L}$ template DNA, $0.25 \mu \mathrm{M}$ of each primer (F: 5'-ATGAATACTTATTTTGATAT and R: CTAAATCCATGCTCTGACCC-3'), 0.2 $\mathrm{mM}$ deoxyribonucleoside triphosphates, $1 \mathrm{X}$ reaction buffer, $2 \mathrm{mM} \mathrm{MgCl}_{2}$ and $1.5 \mathrm{U}$ Taq DNA polymerase (Fermentas) in a total volume of $25 \mu \mathrm{L}$. The DNA was amplified using the following protocol: initial denaturation $\left(94^{\circ} \mathrm{C}\right.$ for 5 min), followed by 25 cycles of denaturation $\left(94^{\circ} \mathrm{C}\right.$ for 35 s), annealing $\left(53^{\circ} \mathrm{C}\right.$ for $\left.45 \mathrm{~s}\right)$ and extension $\left(72^{\circ} \mathrm{C}\right.$ for $\left.1 \mathrm{~min}\right)$, with a single final extension of $7 \mathrm{~min}$ at $72^{\circ} \mathrm{C}$.

\subsection{PCR Amplification of Virulence Genes}

Three different multiplex PCR assays were used in order to amplify various virulence genes. The programmable thermal cycler (Eppendorf, Mastercycler@ 5330, Eppendorf-Netheler-Hinz GmbH, Hamburg, Germany) PCR device was used in all PCR reactions. The first multiplex PCR reaction was used for the detection of $\operatorname{alg} D$ and $\operatorname{alg} U$ virulence genes of $P$. aeruginosa isolated from clinical samples. The PCR reaction was performed in a total volume of $50 \mu \mathrm{L}$, containing $2.5 \mu \mathrm{L}$ of DNA template, $1.5 \mathrm{mM} \mathrm{MgCl} 2,200 \mu \mathrm{M}$ dNTP (Fermentas), $0.5 \mu \mathrm{M}$ of each primer ( $\operatorname{alg} D \mathrm{~F}$ : 5'-AAGGCGGAAATGCCATCTCC-3' and $\operatorname{algDR}$ : 5'-AGGGAAGTTCCGGGCGTTTG-3' (21) as well as algUF: 5'CGCGAACCGCACCATCGCTC-3' and algUR: 5'-GCCGCACGTCACGAGC-3') (22), 1.25 U Taq DNA polymerase(Fermentas), and $5 \mu \mathrm{L}$ PCR buffer $10 \mathrm{X}$. Reactions were initiated with 1 cycle, at $95^{\circ} \mathrm{C}$ for $2 \mathrm{~min}$, followed by 30 cycles at $94^{\circ} \mathrm{C}$ for $30 \mathrm{~s}, 58^{\circ} \mathrm{C}$ for $30 \mathrm{~s}, 72^{\circ} \mathrm{C}$ for $1 \mathrm{~min}$ and a final elongation 
Fazeli N et al.

step at $72^{\circ} \mathrm{C}$ for $7 \mathrm{~min}$. The second multiplex PCR reaction was used for detection of lasB, toxA, plcH, plcN, and exoS virulence genes of $P$. aeruginosa isolated from clinical samples. List of the primers is shown in Table 1(23) 18. The PCR reaction was performed in a total volume of 50 $\mu \mathrm{L}$, containing $25 \mathrm{ng}$ of DNA template, $10 \mathrm{mM}$ Tris- $\mathrm{HCl}, 50$ $\mathrm{nmol} \mathrm{KCl,} 1.5 \mathrm{mM} \mathrm{MgCl}, 200 \mu \mathrm{M}$ dNTP (Fermentas), 12.5 pmol of each primer, 1 U Taq DNA polymerase (Fermen- tas) and $5 \mu \mathrm{L}$ PCR buffer $10 \mathrm{X}$. Reactions were initiated at 1 cycle at $94^{\circ} \mathrm{C}$ for $3 \mathrm{~min}$, followed by 30 cycles at $94^{\circ} \mathrm{C}$ for $30 \mathrm{~s}, 55$ for $1 \mathrm{~min}, 72^{\circ} \mathrm{C}$ for $1.5 \mathrm{~min}$ and a final elongation step at $72^{\circ} \mathrm{C}$ for $5 \mathrm{~min}$. The third multiplex PCR reaction based on the method of Finnan et al. (7) and was used for the detection of exoT, exoY, exoU, apr, phzH, phzM, phzI, ph$z I I, p h z S$, lasA, pvdA, pilA and pilB virulence genes. Table 1 shows the list of primers.

\begin{tabular}{|c|c|c|}
\hline Gene & Sequence (5'-3') & Size of Product (bp) \\
\hline \multirow[t]{2}{*}{ lasB } & lasB F: GGAATGAACGAAGCGTTCTCCGAC & 284 \\
\hline & lasB R: TGGCGTCGACGAACACCTCG & \\
\hline \multirow[t]{2}{*}{ toxA } & toxA F: CTGCGCGGGTCTATGTGCC & 270 \\
\hline & toxA R: GATGCTGGACGGGTCGAG & \\
\hline \multirow[t]{2}{*}{ plcH } & plcH F: GCACGTGGTCATCCTGATGC & 608 \\
\hline & plcH R: TCCGTAGGCGTCGACGTAC & \\
\hline \multirow[t]{2}{*}{ plcN } & plcN F: TCCGTTATCGCAACCAGCCCTACG & 481 \\
\hline & plcN R: TCGCTGTCGAGCAGGTCGAAC & \\
\hline \multirow[t]{2}{*}{ exos } & exoS F: CGTCGTGTTCAAGCAGATGGTGCTG & 444 \\
\hline & exoS R: CCGAACCGCTTCACCAGGC & \\
\hline \multirow[t]{2}{*}{ exot } & exoTF: CAATCATCTCAGCAGAACCC & 1159 \\
\hline & exoT R: TGTCGTAGAGGATCTCCTG & \\
\hline \multirow[t]{2}{*}{ exoY } & exoY F: TATCGACGGTCATCGTCAGGT & 1035 \\
\hline & exoY R: TTGATGCACTCGACCAGCAAG & \\
\hline \multirow[t]{2}{*}{ exoU } & exoU F: GATTCCATCACAGGCTCG & 3308 \\
\hline & exoU R: CTAGCAATGGCACTAATCG & \\
\hline \multirow[t]{2}{*}{ apr } & apr F: TGTCCAGCAATTCTCTTGC & 1017 \\
\hline & apr R: CGTTTTCCACGGTGACC & \\
\hline \multirow[t]{2}{*}{ phzII } & phzII F: GCCAAGGTTTGTTGTCGG & 1036 \\
\hline & phzII R: CGCATTGACGATATGGAAC & \\
\hline \multirow[t]{2}{*}{ phzM } & phzM F: ATGGAGAGCGGGATCGACAG & 875 \\
\hline & phzM R: ATGCGGGTTTCCATCGGCAG & \\
\hline \multirow[t]{2}{*}{ phzS } & phzS F: TCGCCATGACCGATACGCTC & 1752 \\
\hline & phzS R: ACAACCTGAGCCAGCCTTCC & \\
\hline \multirow[t]{2}{*}{ phzI } & phzI F: CATCAGCTTAGCAATCCC & 392 \\
\hline & phzI R: CGGAGAAACTTTTCCCTC & \\
\hline \multirow[t]{2}{*}{ phzH } & phzII F: GGGTTGGGTGGATTACAC & 1752 \\
\hline & phzII R: CTCACCTGGGTGTTGAAG & \\
\hline \multirow[t]{2}{*}{ lasA } & lasA F: GCAGCACAAAAGATCCC & 1075 \\
\hline & lasA R: GAAATGCAGGTGCGGTC & \\
\hline \multirow[t]{2}{*}{$p v d A$} & pvdA F: GACTCAGGCAACTGCAAC & 1281 \\
\hline & $p v d A$ R: TTCAGGTGCTGGTACAGG & \\
\hline \multirow[t]{2}{*}{ pilA } & pilA F: ACAGCATCCAACTGAGCG & 1675 \\
\hline & pilA R:TTGACTTCCTCCAGGCTG & \\
\hline \multirow[t]{2}{*}{ pilB } & pilB F: TCGAACTGATGATCGTGG & 408 \\
\hline & pilB R: CTTTCGGAGTGAACATCG & \\
\hline
\end{tabular}


Fazeli Net al.

\subsection{PCR Amplification of Antibiotic Resistance Genes}

Various $\beta$-lactamase genes and the genes that encode DNA gyrAse (gyrA) and topoisomerase IV (parC) were detected using two separate multiplex PCR assays. Primers gyrA-F (5'-GTGTGCTTTATGCCATGAG-3') and gyrA-R (5'-GGTTTCCTTTTCCAGGTC-3') (24) were used to amplify $287 \mathrm{bp}$ of the fluoroquinolone resistance-determining region of the gyrA gene. Primers parC-F (5'- CATCGTCTACGCCATGAG-3') and parC-R (5'-AGCAGCACCTCGGAATAG-3') (24) were used to amplify $267 \mathrm{bp}$ of the fluoroquinolone resistance-determining region of parC. PCR amplification was performed in a $50 \mu \mathrm{L}$ mixture, containing $1 \times$ PCR buffer, $2.5 \mathrm{mM} \mathrm{MgCl}_{2}, 0.2 \mathrm{mM}$ mix of deoxynucleotide triphosphates (Fermentas), 10 pmol of each primer, $1 \mathrm{U}$ of Taq DNA Polymerase (Fermentase), and $150 \mathrm{ng}$ of the DNA template. Amplification of the target regions was performed in 35 cycles consisting of initial heat activation at $95{ }^{\circ} \mathrm{C}$ for $6 \mathrm{~min}$, denaturation at $95^{\circ} \mathrm{C}$ for $45 \mathrm{~s}$, annealing at $51^{\circ} \mathrm{C}$ for $45 \mathrm{~s}$ and elongation at $72^{\circ} \mathrm{C}$ for $1 \mathrm{~min}$, with a final elongation at $72^{\circ} \mathrm{C}$ for $7 \mathrm{~min}$. List of primers used for detection of various $\beta$-lactamase genes is shown in Table 218 . The PCR reaction was performed in a total volume of $25 \mu \mathrm{L}$, containing $2 \mu \mathrm{L}$ of DNA template, $1.4 \mathrm{mM} \mathrm{MgCl}_{2}, 150$ $\mu \mathrm{M}$ of each dNTP(Fermentas), $0.3 \mu \mathrm{M}$ of each primers and $1 \mathrm{U}$ Taq DNA polymerase (Fermentas). The cycling parameters used were as previously described (18).

\subsection{Gel Electrophoresis}

Fifteen microliter of PCR products were resolved on a $1.5 \%$ agarose gel containing $0.5 \mathrm{mg} / \mathrm{mL}$ of ethidium bromide in Tris-borate-EDTA buffer at $90 \mathrm{~V}$ for 1 hour, also using suitable molecular weight markers. The products were examined under ultraviolet illumination.

\subsection{Statistical Analysis}

The results were transferred to a Microsoft Excel spreadsheet (Microsoft Corp., Redmond, WA) for analysis. Statistical analysis was performed using SPSS/16.0 software (SPSS Inc., Chicago, IL) for finding significant relationships among incidences of bacteria in males and females, virulence gene and pattern of resistance of $P$. aeruginosa isolated from clinical samples. $\chi 2$ test and Fisher exact 2-tailed test analysis were performed in this study. Statistical significance was regarded at a P value $<0.05$.

\subsection{Ethical Considerations}

The present study was accepted by the ethics committees of the Baqiyatallah and Payambaran hospitals, Tehran, Iran and Microbiology and Infectious Diseases Center of the Islamic Azad University of Shahrekord Branch, Iran. Written informed consents were obtained from all the study patients or their parents.

\section{Results}

All the human clinical samples were examined using culture and PCR techniques. Out of 217 clinical samples, 102 (47\%) were positive for $P$. aeruginosa (Table 3 ). In addition, 58 out of 127 male clinical samples (45.66\%) and 44 out of 90 female clinical samples (48.88\%) were positive for $P$. aeruginosa. We found that the patients with respiratory infections had the highest incidence of $P$. aeruginosa (65.21\%), while the patients with UTIs had the lowest incidence (21.95\%). Table 4 presents the antimicrobial resistance in the $P$. aeruginosa isolates from the human clinical samples. Bacterial strains exhibited the highest level of resistance to penicillin (100\%), followed by tetracycline (90.19\%), streptomycin (64.70\%), and erythromy$\operatorname{cin}(43.13 \%)$.

\begin{tabular}{|c|c|c|c|}
\hline Antimicrobial Agent & Resistance Gene & Sequence (5'-3') & Size of Product (bp) \\
\hline \multirow[t]{3}{*}{$\beta$-lactamase } & $b l a_{\mathrm{TEM}}$ & F: ATGAGTATTCAACATTTCCG & 867 \\
\hline & & R: GGACTCTGCAACAAATACGC & \\
\hline & & R: CTGACAGTTACCAATGCTTA & \\
\hline \multirow[t]{2}{*}{$\beta$-lactamase } & $b l a_{\mathrm{SHV}}$ & F: GGTTATGCGTTATATTCGCC & 867 \\
\hline & & R:TTAGCGTTGCCAGTGCTC & \\
\hline \multirow[t]{2}{*}{$\beta$-lactamase } & bla $_{\mathrm{OXA}}$ & F: ACACAATACATATCAACTTCGC & 814 \\
\hline & & R: AGTGTGTTTAGAATGGTGATC & \\
\hline \multirow[t]{2}{*}{$\beta$-lactamase } & ${ }^{b l a} a_{\mathrm{CTX}-\mathrm{M}}$ & F: ATGTGCAGYACCAGTAARGT & 593 \\
\hline & & R: TGGGTRAARTARGTSACCAGA & \\
\hline \multirow[t]{2}{*}{$\beta$-lactamase } & $b l a_{\mathrm{DHA}}$ & F: CACACGGAAGGTTAATTCTGA & 970 \\
\hline & & R: CGGTTARACGGCTGAACCTG & \\
\hline$\beta$-lactamase & $b l a_{\mathrm{VEB}}$ & F: CGACTTCCATTTCCCGATGC & 642 \\
\hline
\end{tabular}


Table 3. Distribution of Pseudomonas aeruginosa in Various Source of Infection According to the Gender ${ }^{\text {a }}$

\begin{tabular}{|ccc}
\hline Source of Isolation & Number of Patients & Number of Positive Samples, No.(\%) \\
\hline Wound infection & 41 & $20(48.78)$ \\
\hline M & 21 & $16(76.19)$ \\
F & 14 & $8(57.14)$ \\
Respiratory infection & 9 & $7(77.77)$ \\
\hline M & & $6(24)$ \\
\hline F & 25 & $3(18.75)$ \\
Urinary tract infection & 16 & $10(45.45)$ \\
M & & $6(35.29)$ \\
\hline F & 22 & $14(56)$ \\
Bed ulcer & 17 & $12(44.44)$ \\
\hline M & & \\
\hline F & 25 & $58(45.66)$ \\
\hline Burn & 27 & $44(48.88)$ \\
\hline M & & \\
\hline F & 127 & \\
\hline Total & 90 & \\
\hline M & & \\
\hline F & & \\
\hline
\end{tabular}

a Abbreviations: M, male; F, female.

Table 4. Antimicrobial Resistance Properties in Pseudomonas aeruginosa Isolated From Clinical Infections in Human a,b

\begin{tabular}{llllllll}
\hline Source of Isolation & P.aeruginosa Iso- & TE30 & S10 & C30 & SXT GM10 NFx5 CF30 CIP5 TMP5 F/M300 AM10 P10 E15
\end{tabular}

\section{Wound infection}

$\begin{array}{lllllllllllllll}\text { M } & 20 & 19 & 17 & 3 & 10 & 5 & 5 & 5 & 4 & 8 & 2 & 4 & 20 & 6 \\ \text { F } & 16 & 15 & 12 & 2 & 6 & 7 & 4 & 4 & 3 & 6 & 1 & 8 & 16 & 3 \\ \text { Respiratory infection } & & & & & & & & & & & & & & \\ \text { M } & 8 & 8 & 5 & 2 & 4 & 2 & 3 & 3 & 3 & 1 & 1 & 2 & 8 & 4 \\ \text { F } & 7 & 7 & 3 & 1 & 2 & 3 & 2 & 2 & 1 & 2 & - & - & 7 & 2\end{array}$

\section{Urinary tract infection}

$\begin{array}{lcccccccccccccccccccccc}\text { M } & 6 & 5 & 3 & 1 & 5 & - & 2 & 2 & 2 & 3 & - & - & 6 & 1 \\ \text { F } & 3 & 2 & 2 & 1 & 1 & 1 & 2 & 2 & 1 & - & - & 1 & 3 & 1 \\ \text { Bed ulcer } & & & & & & & & & & & & & & \\ \text { M } & 10 & 8 & 5 & 2 & 3 & 4 & 3 & 3 & 2 & 7 & 1 & 4 & 10 & 5 \\ \text { F } & 6 & 5 & 3 & 1 & - & 2 & 2 & 2 & 1 & 2 & - & 2 & 6 & 3\end{array}$

\section{Burn}

\begin{tabular}{cccccccccccccccc} 
M & 14 & 12 & 10 & 2 & 4 & 10 & 3 & 3 & 3 & 3 & 1 & 6 & 14 & 12 \\
F & 12 & 11 & 6 & 2 & 8 & 6 & 2 & 2 & 2 & 6 & 1 & 3 & 12 & 7 \\
Total & & & & & & & & & & & & & & \\
M & 58 & 52 & 40 & 10 & 26 & 21 & 16 & 16 & 14 & 22 & 5 & 16 & 58 & 28 \\
F & 44 & 40 & 26 & 7 & 17 & 19 & 12 & 12 & 8 & 16 & 2 & 13 & 44 & 16 \\
\hline
\end{tabular}

a Abbreviations: M, male; F, female.

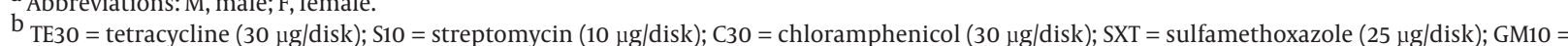

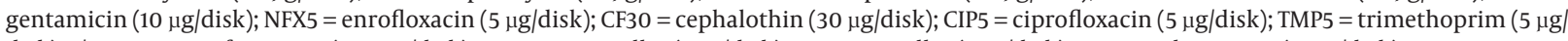

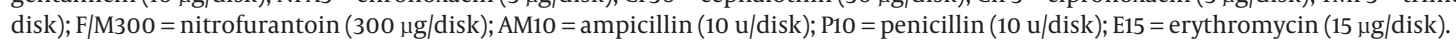


Distribution of antimicrobial resistance genes within the $P$. aeruginosa isolates from the human clinical samples is shown in Table 5 . Genes that encode resistance to $\beta$-lactams antibiotics such as bla $a_{\mathrm{TEM}}(94.11 \%)$, bla $_{\mathrm{DHA}}(21.56 \%)$, and bla $_{\mathrm{C}}$ TX-M $(18.62 \%)$ and the genes that encode resistance to fluoroquinolones, like gyrA (15.68\%) were the most common antibiotic resistance genes in the human clinical samples. Interestingly, we found that males had the highest frequency of antibiotic resistance genes. Table 6 shows the distribution of virulence genes in the P. aeruginosa isolates from the human clinical samples. The most commonly detected virulence genes of $P$. aeruginos $a$ isolates from the human clinical samples were exoS (67.64\%), plcH (45.09\%), phzM (36.27\%), exoT(36.27\%), toxA (35.29\%), and pilA (34.31\%). Moreover, we found that isolates of burn infection had the highest frequency of virulence genes. The PCR results for detection of some virulence and antibiotic resistance genes are shown in Figures 1, 2, and 3.

\begin{tabular}{|c|c|c|c|c|c|c|c|c|c|}
\hline Source of Isolation & P. aeruginosa Isolates & bla $_{\text {TEM }}$ & bla $_{\text {SHV }}$ & bla $_{\text {OXA }}$ & bla $_{\mathrm{CTX}-\mathrm{M}}$ & bla $_{\text {DHA }}$ & bla $_{\mathrm{VEB}}$ & gyrA & parC \\
\hline \multicolumn{10}{|l|}{ Wound infection } \\
\hline M & 20 & 20 & 2 & - & 1 & 2 & - & 1 & - \\
\hline $\mathrm{F}$ & 16 & 16 & 4 & 2 & 2 & 1 & - & 2 & 1 \\
\hline \multicolumn{10}{|l|}{ Respiratory infection } \\
\hline $\mathrm{M}$ & 8 & 7 & 1 & 2 & 1 & 2 & 1 & - & - \\
\hline $\mathrm{F}$ & 7 & 6 & 2 & - & - & 1 & - & - & - \\
\hline \multicolumn{10}{|c|}{ Urinary tract infection } \\
\hline M & 6 & 5 & - & 4 & 1 & 2 & 1 & 2 & - \\
\hline $\mathrm{F}$ & 3 & 3 & 1 & - & 1 & 2 & - & - & 1 \\
\hline \multicolumn{10}{|l|}{ Bed ulcer } \\
\hline M & 10 & 10 & 2 & 3 & 4 & 4 & 1 & 2 & - \\
\hline F & 6 & 5 & - & 1 & - & - & 2 & 2 & 1 \\
\hline \multicolumn{10}{|l|}{ Burn } \\
\hline M & 14 & 14 & 3 & 4 & 7 & 6 & 7 & 5 & - \\
\hline $\mathrm{F}$ & 12 & 10 & 2 & - & 2 & 2 & 6 & 2 & - \\
\hline \multicolumn{10}{|l|}{ Total } \\
\hline M & 58 & 56 & 8 & 13 & 14 & 16 & 10 & 10 & - \\
\hline $\mathrm{F}$ & 44 & 40 & 9 & 3 & 5 & 6 & 8 & 6 & 3 \\
\hline
\end{tabular}

\begin{tabular}{|c|c|c|c|c|c|c|c|c|c|c|c|c|c|c|c|c|c|c|c|c|c|c|}
\hline $\begin{array}{l}\text { Source of } \\
\text { Isolation }\end{array}$ & $\begin{array}{l}\text { P. aeru- } \\
\text { ginosa } \\
\text { isolates }\end{array}$ & exoT & exoY & exos & exoU & phzH & apr & phzI & phzN & phz & phz & $\operatorname{las} A$ & lasB & pvdA & pilA & pilB & toxA & algD & algU & plcH & plcN & nan1 \\
\hline \multicolumn{23}{|l|}{$\begin{array}{l}\text { Wound } \\
\text { infection }\end{array}$} \\
\hline M & 20 & 5 & 7 & 18 & - & 1 & 2 & - & 1 & - & 1 & - & 1 & 2 & 10 & 2 & 4 & 2 & 5 & 11 & 6 & 1 \\
\hline $\mathrm{F}$ & 16 & 2 & 6 & 11 & 2 & - & 1 & 8 & 3 & 2 & - & 2 & 3 & 8 & 1 & 6 & 3 & 1 & 2 & 7 & 11 & 2 \\
\hline \multicolumn{23}{|l|}{$\begin{array}{l}\text { Respi- } \\
\text { ratory } \\
\text { infection }\end{array}$} \\
\hline M & 8 & 1 & 3 & 6 & 2 & 2 & - & 2 & 4 & 1 & 1 & 1 & 2 & 1 & 2 & 1 & - & - & 1 & 4 & 3 & - \\
\hline $\mathrm{F}$ & 7 & 4 & 1 & 3 & - & - & 2 & 1 & 2 & - & 1 & 2 & 3 & 1 & 3 & 2 & 5 & - & - & 5 & 2 & 2 \\
\hline \multicolumn{23}{|l|}{$\begin{array}{l}\text { Urinary } \\
\text { tract in- } \\
\text { fection }\end{array}$} \\
\hline M & 6 & 3 & - & 2 & 1 & - & 1 & 3 & 3 & 1 & 1 & 1 & - & 2 & 1 & - & 4 & - & 3 & - & 2 & - \\
\hline F & 3 & 1 & 1 & 1 & - & 2 & - & - & 1 & - & 1 & 1 & 1 & - & - & 1 & 2 & - & - & - & - & - \\
\hline \multicolumn{23}{|l|}{ Bed ulcer } \\
\hline M & 10 & 7 & 4 & 7 & 3 & 4 & - & 4 & 6 & 2 & 1 & 5 & - & 2 & 4 & - & 8 & - & 7 & 4 & - & 6 \\
\hline F & 6 & 2 & - & 2 & - & 1 & 2 & 1 & 1 & 2 & - & 2 & 1 & 1 & 2 & 1 & - & - & 2 & 2 & 1 & 2 \\
\hline \multicolumn{23}{|l|}{ Burn } \\
\hline M & 14 & 10 & 5 & 11 & 4 & 7 & 4 & 6 & 9 & 3 & 8 & 7 & 2 & 6 & 7 & 3 & 9 & 2 & 10 & 8 & 6 & 8 \\
\hline F & 12 & 2 & 6 & 8 & 2 & 4 & 3 & 4 & 7 & 2 & 6 & 6 & 5 & 2 & 5 & 2 & 1 & 3 & 2 & 5 & 3 & 3 \\
\hline \multicolumn{23}{|l|}{ Total } \\
\hline M & 58 & 26 & 19 & 44 & 10 & 14 & 7 & 15 & 23 & 7 & 12 & 14 & 5 & 13 & 24 & 6 & 25 & 4 & 26 & 27 & 17 & 15 \\
\hline $\mathrm{F}$ & 44 & 11 & 4 & 25 & 4 & 7 & 6 & 14 & 14 & 6 & 8 & 13 & 13 & 12 & 11 & 12 & 11 & 4 & 6 & 19 & 17 & 9 \\
\hline
\end{tabular}


Fazeli N et al.

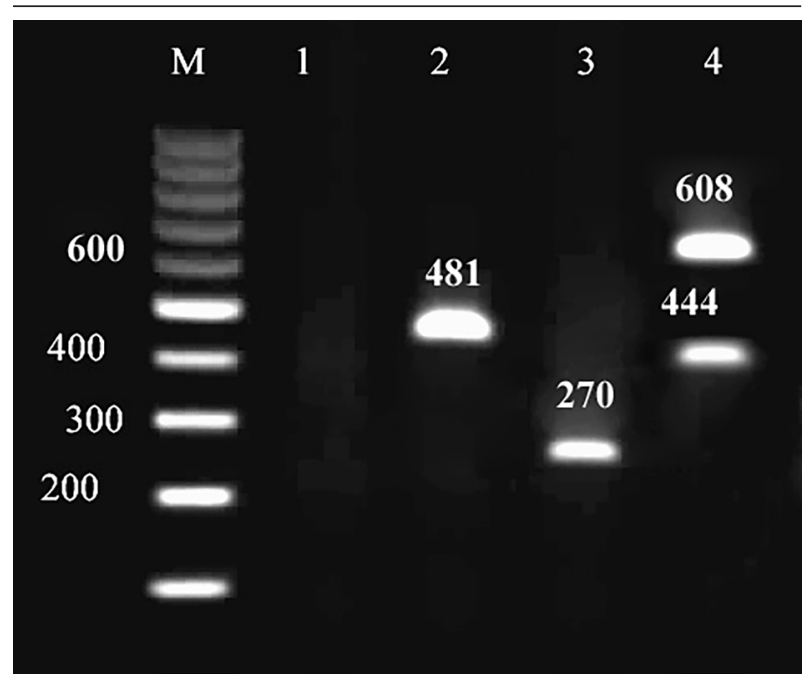

Figure 1. Agarose Gel Electrophoresis of PCR Products Amplified With a Multiplex PCR Method for the plcN (481 bp), toxA (270 bp), exoS (444 bp), and plcH (608 bp) Genes From Pseudomonas aeruginosa. $\mathrm{M}=100$-bp DNA Ladder.

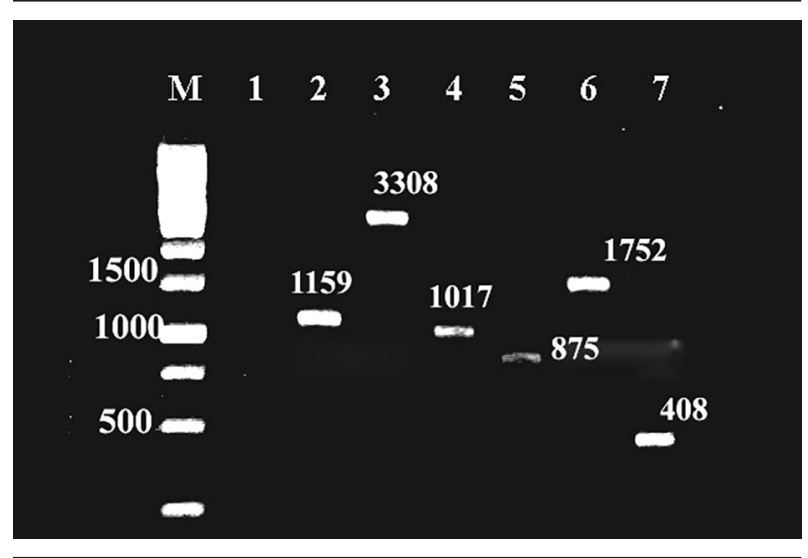

Figure 2. Agarose Gel Electrophoresis of PCR Products Amplified With a Multiplex PCR Method for the exoT (1159 bp), exoU (3308 bp), apr (1017 bp), phzM (875 bp), phzS (1752 bp), and pilB (408 bp) genes From Pseudomonas aeruginosa. $\mathrm{M}=1-\mathrm{kb}$ DNA Ladder.

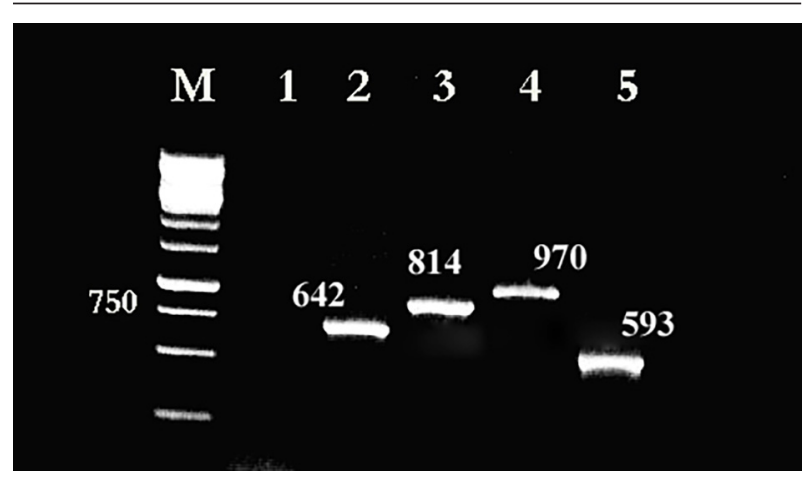

Figure 3. Agarose Gel Electrophoresis of PCR Products Amplified With a Multiplex PCR Method for the blaVEB (642 bp), blaOXA (814 bp), blaDHA (970 bp), and blaCTX-M (593 bp) Genes From Pseudomonas aeruginosa. M $=1-\mathrm{kb}$ DNA Ladder.

\section{Discussion}

The results of the present study showed that multidrug resistant $P$. aeruginosa is one of the main active pathogens in human clinical samples, especially wound infections, respiratory infections, UTIs, bed ulcer, and burn infections. Also, our results showed that antibiotics were used in an irregular manner in Iranian hospitals. These two findings may lead to the emergence of resistant Pseudomonas strains, which can infect patients and even healthy people in hospitals.

Similar results have been reported by Zavascki et al. $(25,26)$, Lanini et al. (27), and Pitten et al. (28). Statistical analyses showed a significant $(\mathrm{P}<0.01)$ association between the incidence of $P$. aeruginosa in respiratory infections (65.21\%) and UTIs (21.95\%). The high incidences of $P$. aeruginosa in respiratory infections have been previously reported (29-31). In the Viedma et al. (32) study, the main clinical wards in which drug-resistant $P$. aeruginosa strains were isolated included internal medicine (31.1\%), surgery (17.5\%), intensive care (13.1\%), pulmonology (11.5\%), and hematology (8.2\%). Also, Viedma et al. (32) showed that out of 183 patients, 143 (78.1\%) were considered infected, including 36 (19.7\%) patients with lower respiratory tract infection, 30 (16.4\%) patients with urinary tract infection, 28 (15.3\%) patients with bacteremia, and 22 (12\%) patients with intra-abdominal infection.

There were significant differences $(P<0.01)$ in the incidence of $P$. aeruginosa strains between male and female patients. Al-Hasan et al. (33) reported that $62.80 \%$ of $P$. aeruginosa strains were isolated from hospitalized males. Also, gender-wise prevalence showed 61.78\% male and $38.22 \%$ females of the study of Khan et al. (34) were infected by $P$. aeruginosa, which was similar to our results. One possible explanation for the high prevalence of $P$. aeruginosa in male patients lies in their jobs, which usually included hard works outside the house, while Iranian women are typically housewives. Therefore, they are away from contaminated work environments.

The overall incidence of $P$. aeruginosa in human clinical samples of our study was $47 \%$. Similar incidence rates have been reported from India (29.6\%) (35), Georgia (31.5\%) (36), Norway and Sweden (25.8 to $45.9 \%$ ) (37), Turkey (16.4\%) (38), and Brazil (37.3\%) (25). The overall incidence for $P$. aeruginosa was 6.4 cases/100,000 population in England, Wales and Northern Ireland (39). Infections were reported more among those aged 75 years and older, especially among male patients with a rate of 52.0 cases/100,000 population compared with 19.7 cases/100,000 for female patients (the same age group) (40). Tacconelli et al. (40) reported that out of 358 patients with $P$. aeruginosa bacteremia, 133 (37\%) were hospitalized in medical wards, 103 (29\%) in ICUs, 97 (27\%) in surgical wards, and 25 (7\%) in neonatology wards, 45 (12\%) patients had HIV infection and 28 (8\%) had hematologic malignancies.

Similar investigations have been done on Iranian hospitals infections (41-50). Bacterial strains of our investiga- 
tion were multidrug resistant. All isolates were resistant to penicillin which shows the irregular and extreme prescription of this antibiotic. There were significant differences $(P<0.01)$ in the distribution of antimicrobial resistance among penicillin, nitrofurantoin, and chloramphenicol $(\mathrm{P}<0.05)$ and among resistance to penicillin and ampicillin, ciprofloxacin, enrofloxacin, and gentamicin. Majority of the P. aeruginosa strains of the Japoni et al. (51) investigation were resistant to more than 5 antibiotics which was similar to our results. Shiny et al. (52) reported that out of the 500 pus and 500 urine samples screened, the percentage positivity of $P$. aeruginosa were $12.8 \%$ (53) and $4 \%(20)$, respectively and all (100\%) samples were sensitive to imipenem, while resistance was maximum to cefotaxime (93.75\%). In a study of Viedma et al. (32), which was conducted from 2007 to 2010, the prevalence of $P$. aeruginosa had increased from $2.8 \%$ to $15.3 \%$ over this period and all the isolates were only susceptible to colistin (100\%) and amikacin (75\%). High antibiotic resistances against penicillin, tetracycline, streptomycin, and erythromycin have been previously reported too $(15$, 17). Our results showed that $39.21 \%$ and $21.56 \%$ of bacterial strains were resistant to gentamicin and ciprofloxacin, respectively. Fazeli et al. (54) showed that 29\% and 32.2\% of the $P$. aeruginosa strains were resistant to ciprofloxacin and gentamicin, which was similar to our results. Ciprofloxacin has been stated to be the most potent available drug for the treatment of P. aeruginosa infections (55). Resistance of $P$. aeruginosa to ciprofloxacin was $21.56 \%$, compared with $26.8 \%$ in Latin America (56) and 10\%-32\% in Europe $(57,58)$.

The antibiotic resistant pattern found by Akingbade et al. (15) investigation showed that $P$. aeruginosa, on one hand, had high resistant to amoxicillin (92.7\%), ampicillin (90\%), cloxacillin (88.2\%), cotrimoxazole (77.3\%), erythromycin (72.7\%), tetracycline (70.9\%), streptomycin (65.5\%), and ofloxacin (690\%), and on the other hand, had low resistant to ceftazidime (20\%), gentamicin (26.4\%), levoxin (30.9\%), ceftriaxone (34.5\%), and ciprofloxacin (35.5\%), which was similar to our results. Our results also showed that $16.66 \%$ and $6.86 \%$ of our bacterial strains were resistant to chloramphenicol and nitrofurantoin, respectively. Similar results have been reported by Lim et al. (18) from Malaysia and Smith et al. (59) from Nigeria. Chloramphenicol and nitrofurantoin are banned antibiotics and the slight antibiotic resistance to these drugs detected in our study indicates that irregular and unauthorized use of them may have occurred in Iran.

Several genes which encode resistance to $\beta$-lactams antibiotics such as bla $a_{\mathrm{TEM}}(94.11 \%), b_{\mathrm{DHA}}(21.56 \%)$, blaOXA $(15.68 \%), b l a_{\mathrm{VEB}}(17.64 \%), b l a_{\mathrm{SHV}}(16.66 \%)$, and bla $a_{\mathrm{CTX}-\mathrm{M}}$ (18.62\%) and the genes that encode resistance to fluoroquinolones like gyrA (15.68\%) and parC (2.94\%) were detected in the bacterial strains of our study. There were statistically significant differences $(P<0.05)$ amongst the incidences of genes encoding resistance to $\beta$-lactams and those encoding resistance to fluoroquinolones. Also, sta- tistical analyses showed a significant $(\mathrm{P}<0.05)$ association between the incidence of $b l a_{\mathrm{TEM}}$ and other genes encoding resistance to $\beta$-lactams. There were no significant differences between the incidence of gyrA and parC genes. Of $82 P$. aeruginosa stains isolated from human clinical specimens, $15 \%, 74 \%, 74 \%, 76 \%, 82 \%$, and $76 \%$ had tet $A$, tetB, $b l a_{\mathrm{VIM} 2 \mathrm{a}}, b l a_{\mathrm{VIM} 2 \mathrm{~b}}, a a c A$, and $b l a_{\mathrm{OXA}}$, respectively. A recent study performed within our region in Egypt reported that the majority (97\%) of P. aeruginosa isolates were beta-lactamase producers (3). P. aeruginosa isolates of the Du et al. (60) study showed the high incidence of antibiotic resistance genes, including bla $a_{\mathrm{TEM}-1}(100 \%)$, bla $\mathrm{PSE}-1$ (100\%), bla OXA-2 $_{2}(96.2 \%)$, bla $_{S H V-18}(91.3 \%)$, bla $_{\text {OXA-17 }}(78.3 \%)$, bla $_{\text {VIM-3 }}(26.1 \%), b_{O X A-10}(21.7 \%)$, and bla SHV-1 $_{-1}(8.7 \%)$. In the human isolates, the most prevalent extended-spectrum $\beta$-Lactamases (ESBLs) in P. aeruginosa are bla ${ }_{S H V-5}$ and bla $_{S H V-12}$ in Taiwan (61). However, in the present study, we found that bla $a_{\mathrm{TEM}}(94.11 \%)$ and bla $\mathrm{DHA}$ (21.56\%) were the most commonly detected antibiotic resistance genes.

The results of disk diffusion method were confirmed the results of PCR amplification of resistance genes. Our results indicated the high presence of virulence factors in $P$. aeruginosa isolates. Totally, exoS (67.64\%) and $\mathrm{plcH}$ (45.09\%) were the most commonly detected virulence genes. There were statistically significant differences $(\mathrm{P}<0.05)$ amongst the incidences of exoS and exoT and exoU, also $\mathrm{P}<0.05$ amongst the incidences of $p h z M$ and phzI, phzS and phzH genes. There were no significant differences amongst the incidences of las $A, \operatorname{lasB}, \mathrm{plcH}$, and plcN. Also, statistical analyses showed a significant ( $\mathrm{P}$ $<0.05$ ) association between the incidences of pilA, pilB, $a \lg D$, and $\operatorname{alg} U$. The exoS gene is directly translocated into eukaryotic cells by the contact-dependent type III secretory process and, as such, it provides the bacterium with a mechanism for manipulating the eukaryotic cells it encounters. In support of exoS contributing to P. aeruginosa pathogenicity, bacterial translocation of exoS into epithelial cells results in a general inactivation of cellular function, as recognized by the inhibition of DNA synthesis, loss of focal adhesion, cell rounding, and microvillus effacement $(62,63)$. High importance of the exoS, exoU, and exoTgenes of $P$. aeruginosa in the pathogenicity of lung diseases has been reported before (10). Also, the exoS gene contributed to dissemination in burn, lung diseases and keratitis $(10,53,64)$. Our results showed that the exoS gene had the highest incidence in human clinical samples, including wound, respiratory and urinary tract infections, bed ulcer, and burn. The $p l c H$ gene is responsible for proinflammatory activities (9), virulence in animal models (66), pulmonary inflammation (9), and inhibition of oxidative burst of neutrophils (65). Similar results have been reported previously from Malaysia (66), Australia (67), Jamaica (68), and Lebanon (17).

As far as we know, this investigation is the most comprehensive report of virulence factors and antibiotic resistance properties of $P$. aeruginosa isolated from Iranian human clinical samples. Our results revealed that all the 
Fazeli N et al.

exo, apr, phz, las, pvd, pil, tox, alg, plc, and nan virulence genes are predominant in human infections. Antibiotic resistance against penicillin, tetracycline, and streptomycin were high. Prescription of ciprofloxacin, nitrofurantoin, and chloramphenicol can be effective for the treatment of human infections due to $P$. aeruginosa in our area. Hence, judicious use of antibiotics is required by clinicians.

\section{Acknowledgements}

The authors would like to thank Dr. E. Tajbakhsh, and Mr. M. Momeni at Biotechnology Research Center of the Islamic Azad University of Shahrekord for their important technical and clinical support. This work was supported by the Islamic Azad University, Shahrekord Branch, Iran.

\section{Authors' Contributions}

DNA extraction, PCR, manuscript preparation, statistical analysis, and project support were all performed by Hassan Momtaz. Sample collections and coordination was performed by Nastaran Fazeli. All authors have read and approved the final manuscript.

\section{Funding/Support}

This work was supported by the Islamic Azad University, Shahrekord Branch, Iran (grant No. 92/2011).

\section{References}

1. Aloush V, Navon-Venezia S, Seigman-Igra Y, Cabili S, Carmeli Y. Multidrug-resistant Pseudomonas aeruginosa: risk factors and clinical impact. Antimicrob Agents Chemother. 2006;50(1):43-8.

2. Chatzinikolaou I, Abi-Said D, Bodey GP, Rolston KV, Tarrand JJ, Samonis G. Recent experience with Pseudomonas aeruginosa bacteremia in patients with cancer: Retrospective analysis of 245 episodes. Arch Intern Med. 2000;160(4):501-9.

3. Gad GF, El-Domany RA, Zaki S, Ashour HM. Characterization of Pseudomonas aeruginosa isolated from clinical and environmental samples in Minia, Egypt: prevalence, antibiogram and resistance mechanisms. J Antimicrob Chemother. 2007;60(5):1010-7.

4. Hirsch EB, Tam VH. Impact of multidrug-resistant Pseudomonas aeruginosa infection on patient outcomes. Expert Rev Pharmacoecon Outcomes Res. 2010;10(4):441-51.

5. Maschmeyer G, Braveny I. Review of the incidence and prognosis of Pseudomonas aeruginosa infections in cancer patients in the 1990s. Eur J Clin Microbiol Infect Dis. 2000;19(12):915-25.

6. Mavrodi DV, Bonsall RF, Delaney SM, Soule MJ, Phillips G, Thomashow LS. Functional analysis of genes for biosynthesis of pyocyanin and phenazine-1-carboxamide from Pseudomonas aeruginosa PAO1.J Bacteriol. 2001;183(21):6454-65.

7. Finnan S, Morrissey JP, O'Gara F, Boyd EF. Genome diversity of Pseudomonas aeruginosa isolates from cystic fibrosis patients and the hospital environment. J Clin Microbiol. 2004;42(12):578392.

8. Krall R, Schmidt G, Aktories K, Barbieri JT. Pseudomonas aeruginosa ExoT is a Rho GTPase-activating protein. Infect Immun. 2000;68(10):6066-8.

9. Wieland CW, Siegmund B, Senaldi G, Vasil ML, Dinarello CA, Fantuzzi G. Pulmonary inflammation induced by Pseudomonas aeruginosa lipopolysaccharide, phospholipase $\mathrm{C}$, and exotoxin A: role of interferon regulatory factor 1. Infect Immun. 2002;70(3):1352-8.

10. Shaver CM, Hauser AR. Relative contributions of Pseudomonas aeruginosa ExoU, ExoS, and ExoT to virulence in the lung. Infect
Immun. 2004:72(12):6969-77.

11. Lomholt JA, Poulsen K, Kilian M. Epidemic population structure of Pseudomonas aeruginosa: evidence for a clone that is pathogenic to the eye and that has a distinct combination of virulence factors. Infect Immun. 2001;69(10):6284-95.

12. Makedou KG, Tsiakiri EP, Bisiklis AG, Chatzidimitriou M Halvantzis AA, Ntoutsou K, et al. Changes in antibiotic resistance of the most common Gram-negative bacteria isolated in intensive care units. J Hosp Infect. 2005;60(3):245-8.

13. Tsukayama DT, van Loon HJ, Cartwright C, Chmielewski B, Fluit AC, van der Werken C, et al. The evolution of Pseudomonas aeruginosa during antibiotic rotation in a medical intensive care unit: the RADAR-trial. Int J Antimicrob Agents. 2004;24(4):339-45.

14. Shahini N, Shahini N, Ala S. Determining of resistance and sensitivity of Pseudomonas aeruginosa in Iran in 2010-2011. Res Pharm Sci. 2012;7(5):S884.

15. Akingbade O, Balogun S, Ojo D, Afolabi R, Motayo B, Okerentugba $\mathrm{P}$, et al. Plasmid profile analysis of multidrug resistant Pseudomonas aeruginosa isolated from wound infections in South West, Nigeria. World Appl Sci J. 2012;20(6):766-75.

16. Oliver A, Weigel LM, Rasheed JK, McGowan Jr JJ, Raney P, Tenover FC. Mechanisms of decreased susceptibility to cefpodoxime in Escherichia coli.AntimicrobAgents Chemother. 2002;46(12):382936.

17. Tokajian S, Timani R, Issa N, Araj G. Molecular Characterization, Multiple Drug Resistance, and Virulence Determinants of Pseudomonas aeruginosa Isolated from Lebanon. Br Microbiol Res J. 2012;2(4):243-50.

18. Lim KT, Yasin RM, Yeo CC, Puthucheary SD, Balan G, Maning N, et al. Genetic fingerprinting and antimicrobial susceptibility profiles of Pseudomonas aeruginosa hospital isolates in Malaysia. $J$ Microbiol Immunol Infect. 2009;42(3):197-209.

19. Clinical and Laboratory Standards Institute. M100-S22 Performance standards for antimicrobial susceptibility testing 22nd informational supplement. Wayne (PA); CLSI. 2012.

20. Strateva T. Microbiological and molecular-genetic investigations on the resistance mechanisms and virulence factors in clinical strains of Pseudomonas aeruginosa. Medical University of Sofia: Bulgaria; 2008.

21. Wozniak DJ, Ohman DE. Transcriptional analysis of the Pseudomonas aeruginosa genes algR, algB, and algD reveals a hierarchy of alginate gene expression which is modulated by algT. J Bacteriol. 1994;176(19):6007-14.

22. Schurr MJ, Martin DW, Mudd MH, Deretic V. Gene cluster controlling conversion to alginate-overproducing phenotype in Pseudomonas aeruginosa: functional analysis in a heterologous host and role in the instability of mucoidy. $J$ Bacteriol. 1994;176(11):3375-82.

23. Wolska K, Szweda P. Genetic features of clinical Pseudomonas aeruginosa strains. Pol J Microbiol. 2009;58(3):255-60.

24. Gorgani N, Ahlbrand S, Patterson A, Pourmand N. Detection of point mutations associated with antibiotic resistance in Pseudomonas aeruginosa. Int J Antimicrob Agents. 2009;34(5):414-8.

25. Zavascki AP, Barth AL, Fernandes JF, Moro AL, Goncalves AL, Goldani LZ. Reappraisal of Pseudomonas aeruginosa hospitalacquired pneumonia mortality in the era of metallo-beta-lactamase-mediated multidrug resistance: a prospective observational study. Crit Care. 2006;10(4):R114.

26. Zavascki AP, Gaspareto PB, Martins AF, Goncalves AL, Barth AL. Outbreak of carbapenem-resistant Pseudomonas aeruginosa producing SPM-1 metallo-\{beta\}-lactamase in a teaching hospital in southern Brazil. JAntimicrob Chemother. 2005;56(6):1148-51.

27. Lanini S, D'Arezzo S, Puro V, Martini L, Imperi F, Piselli P, et al Molecular epidemiology of a Pseudomonas aeruginosa hospital outbreak driven by a contaminated disinfectant-soap dispenser. PLoS One. 2011;6(2).

28. Pitten FA, Panzig B, Schroder G, Tietze K, Kramer A. Transmission of a multiresistant Pseudomonas aeruginosa strain at a German University Hospital. J Hosp Infect. 2001;47(2):125-30.

29. West SE, Zeng L, Lee BL, Kosorok MR, Laxova A, Rock MJ, et al. Respiratory infections with Pseudomonas aeruginosa in children with cystic fibrosis: early detection by serology and assessment of risk factors. JAMA. 2002;287(22):2958-67. 
30. Martinez-Solano L, Macia MD, Fajardo A, Oliver A, Martinez JL Chronic Pseudomonas aeruginosa infection in chronic obstructive pulmonary disease. Clin Infect Dis. 2008;47(12):1526-33.

31. Tingpej P, Smith L, Rose B, Zhu H, Conibear T, Al Nassafi K, et al Phenotypic characterization of clonal and nonclonal Pseudomonas aeruginosa strains isolated from lungs of adults with cystic fibrosis. JClin Microbiol. 2007;45(6):1697-704.

32. Viedma E, Juan C, Villa J, Barrado L, Orellana MA, Sanz F, et al. VIM-2-producing multidrug-resistant Pseudomonas aeruginosa ST175 clone, Spain. Emerg Infect Dis. 2012;18(8):1235-41.

33. Al-Hasan MN, Wilson JW, Lahr BD, Eckel-Passow JE, Baddour LM. Incidence of Pseudomonas aeruginosa bacteremia: a population-based study. Am J Med. 2008;121(8):702-8.

34. Khan JA, Iqbal Z, Rahman SU, Farzana K, Khan A. Report: prevalence and resistance pattern of Pseudomonas aeruginosa against various antibiotics. PakJ Pharm Sci. 2008;21(3):311-5.

35. Ranjan KP, Ranjan N, Bansal SK, Arora DR. Prevalence of Pseudomonas aeruginosa in post-operative wound infection in a referral hospital in Haryana, India. J Lab Physicians. 2010;2(2):74-7.

36. Burjanadze I, Kurtsikashvili G, Tsereteli D, Tsertsvadze E, Kekelidze M, Imnadze P, et al. Pseudomonas aeruginosa infection in an intensive care unit. Int J Infect Control. 2007;3(2):1-3.

37. Knudsen PK, Olesen HV, Hoiby N, Johannesson M, Karpati F, Laerum BN, et al. Differences in prevalence and treatment of Pseudomonas aeruginosa in cystic fibrosis centres in Denmark, Norway and Sweden. J Cyst Fibros. 2009;8(2):135-42.

38. Savas L, Duran N, Savas N, Onlen Y, Ocak S. The prevalence and resistance patterns of Pseudomonas aeruginosa in intensive care units in a university hospital. Turk J Med Sci. 2005;35(5):317-22.

39. Voluntary surveillance of Pseudomonas spp. and Stenotrophomonas spp. causing bacteraemia in England, Wales and Northern Ireland. 2012.

40. Tacconelli E, Tumbarello M, Bertagnolio S, Citton R, Spanu T, Fadda G, et al. Multidrug-resistant Pseudomonas aeruginosa bloodstream infections: analysis of trends in prevalence and epidemiology. Emerg Infect Dis. 2002;8(2):220-1.

41. Shahcheraghi F, Nikbin VS, Feizabadi MM. Prevalence of ESBLs genes among multidrug-resistant isolates of Pseudomonas aeruginosa isolated from patients in Tehran. Microb Drug Resist 2009;15(1):37-9.

42. Rastegar Lari A, Bahrami Honar H, Alaghehbandan R. Pseudomonas infections in Tohid Burn Center, Iran. Burns. 1998;24(7):637 41.

43. Saderi H, Karimi Z, Owlia P, Bahar MA, Akhavi Rad SMB. Phenotypic detection of metallo-beta-lactamase producing Pseudomonas aeruginosa strains isolated from burned patients. Iran J Pathol. 2008;3(1):20-4

44. Salimi H, Owlia P, Yakhchali B, Rastegar Lari AA. Characterization of Pseudomonas aeruginosa in burn patients using PCR-restriction fragment length polymorphism and random amplified polymorphic DNA analysis. Iran J Med Sci. 2010;35(3):236-41.

45. Moniri R, Mosayebi Z, Movahedian AH, Mousavi GA. Emergence of multi-drug-resistant Pseudomonas aeruginosa isolates in neonatal septicemia. J Infect Dis Antimicrob Agents. 2005;22(2):39-44.

46. Movahedi Z, Pourakbari B, Mahmoudi S, Sabouni F, Ashtian Haghi MT, Hosseinpour Sadeghi R, et al. Pseudomonas aeruginosa infection among cystic fibrosis and ICU patients in the referral children medical hospital in Tehran, Iran. J Prev Med Hyg. 2013;54(1):24-8.

47. Mihani F, Khosravi A. Isolation Of Pseudomonas Aeruginosa Strains Producing Metallo Beta Lactamases From Infections In Burned Patients And Identification Of Bla Imp And Bla Vim Genes By Pcr. Iran J Med Microbiol. 2007.

48. Lari AR, Alaghehbandan R. Nosocomial infections in an Iranian burn care center. Burns. 2000;26(8):737-40.

49. Eftekhar F, Khodadad A, Henry D, Speert DP. Isolation and genetic fingerprinting of Pseudomonas aeruginosa from Iranian patients with cystic fibrosis using RAPDPCR. Iran J Biotechnol. 2003;1(2):95-100

50. Ahangarzadeh Rezaee M, Behzadiyan Nejad Q, Owlia P, Najjar Pirayeh S. $n$ vitro activity of imipenem and ceftazidime against mucoid and non-mucoid strains of Pseudomonas aeruginosa isolated from patients in Iran. Arch Iran Med. 2002;5:251-4

51. Japoni A, Alborzi A, Kalani M, Nasiri J, Hayati M, Farshad S. Susceptibility patterns and cross-resistance of antibiotics against Pseudomonas aeruginosa isolated from burn patients in the South of Iran. Burns. 2006;32(3):343-7.

52. Shiny PA, Rajendran S, Sarayu YL. A comparative analysis of isolation and antibiotic sensitivity pattern of Pseudomonas aeruginosa isolated from pus and urine with special reference to phenotypic and genotypic expression of extended spectrum beta lactamases (ESBLs). J Acad Clin Microbiol. 2013;15(1):3-6.

53. Sun Y, Karmakar M, Taylor PR, Rietsch A, Pearlman E. ExoS and ExoT ADP ribosyltransferase activities mediate Pseudomonas aeruginosa keratitis by promoting neutrophil apoptosis and bacterial survival. J Immunol. 2012;188(4):1884-95.

54. Fazeli H, Akbari R, Moghim S, Narimani T, Arabestani MR, Ghoddousi AR. Pseudomonas aeruginosa infections in patients, hospital means, and personnel's specimens. J Res Med Sci. 2012;17(4):332-7.

55. Gales AC, Jones RN, Turnidge J, Rennie R, Ramphal R. Characterization of Pseudomonas aeruginosa isolates: occurrence rates, antimicrobial susceptibility patterns, and molecular typing in the global SENTRY Antimicrobial Surveillance Program, 19971999. Clin Infect Dis. 2001;32 Suppl 2:S146-55.

56. Brown PD, Izundu A. Antibiotic resistance in clinical isolates of Pseudomonas aeruginosa in Jamaica. Rev Panam Salud Publica. 2004;16(2):125-30

57. Bonfiglio G, Carciotto V, Russo G, Stefani S, Schito GC, Debbia E, et al. Antibiotic resistance in Pseudomonas aeruginosa: an Italian survey. J Antimicrob Chemother.1998;41(2):307-10.

58. Bouza E, Garcia-Garrote F, Cercenado E, Marin M, Diaz MS. Pseudomonas aeruginosa: a survey of resistance in 136 hospitals in Spain. The Spanish Pseudomonas aeruginosa Study Group. Antimicrob Agents Chemother. 1999;43(4):981-2.

59. Smith S, Ganiyu O, John R, Fowora M, Akinsinde K, Odeigah P. Antimicrobial resistance and molecular typing of pseudomonas aeruginosa isolated from surgical wounds in Lagos, Nigeria. Acto Med Iran. 2012;50(6):433-8.

60. Du SJ, Kuo HC, Cheng CH, Fei ACY, Wei HW, Chang SK. Molecula mechanisms of ceftazidime resistance in Pseudomonas aeruginosa isolates from canine and human infections. Vet Med. 2010;55(4):172-82.

61. Yu WL, Chuang YC, Walther-Rasmussen J. Extended-spectrum beta-lactamases in Taiwan: epidemiology, detection, treatment and infection control. J Microbiol Immunol Infect. 2006;39(4):264-77.

62. Olson JC, Fraylick JE, McGuffie EM, Dolan KM, Yahr TL, Frank DW, et al. Interruption of multiple cellular processes in HT-29 epithelial cells by Pseudomonas aeruginosa exoenzyme S. Infect Immun. 1999;67(6):2847-54.

63. Yahr TL, Goranson J, Frank DW. Exoenzyme S of Pseudomonas aeruginosa is secreted by a type III pathway. Mol Microbiol. 1996;22(5):991-1003.

64. Jabalameli F, Mirsalehian A, Khoramian B, Aligholi M, Khoramrooz SS, Asadollahi P, et al. Evaluation of biofilm production and characterization of genes encoding type III secretion system among Pseudomonas aeruginosa isolated from burn patients. Burns. 2012;38(8):1192-7.

65. Terada LS, Johansen KA, Nowbar S, Vasil AI, Vasil ML. Pseudomonas aeruginosa hemolytic phospholipase $C$ suppresses neutrophil respiratory burst activity. Infect Immun. 1999;67(5):2371-6.

66. Idris SN, Desa MN, Aziz MN, Taib NM. Antimicrobial susceptibility pattern and distribution of exoU and exoS in clinical isolates of Pseudomonas aeruginosa at a Malaysian hospital. Southeast Asian JTrop Med Public Health. 2012;43(1):116-23.

67. Bradbury RS, Roddam LF, Merritt A, Reid DW, Champion AC Virulence gene distribution in clinical, nosocomial and environmental isolates of Pseudomonas aeruginosa. J Med Microbiol. 2010;59(Pt 8):881-90.

68. Allydice-Francis K, Brown PD. Diversity of Antimicrobial Resistance and Virulence Determinants in Pseudomonas aeruginosa Associated with Fresh Vegetables.IntJMicrobiol.2012;2012:426241. 